\title{
Sexual Need and Related Stress among Patients with Disability Related To Spinal Cord Injury (SCI) and Their Spouses.
}

\author{
*N.THENMOZHI ( M.Sc N) \\ ** Mrs. Selva Titus (M.sc N) \\ *** Mrs. Rebecca (M.sc N) \\ **** Dr. Raji Mathew
}

\begin{abstract}
Spinal Cord Injury is a global epidemic. It results in partial or complete disability. The life expectancy of these patients is also increased. The rehabilitation team is addressing physical needs. To assess the sexual need and related stress among patients with disability related to SCI and their spouses a descriptive study was conducted in in the Physical Medical and Rehabilitation OPD, Rehabilitation institute of the Christian Medical College, Vellore and the nearby villages in Vellore. The sample size was 30 patients and 30 spouses, chosen by purposive sampling technique. The investigator used a demographic variable Performa, Perception of sexual need was assessed using modified Dr. Williams E Snell's combined Multi Dimensional Sexual Self Concept and Sexuality Scale. Stress level was assessed by using modified Dr.Hari.S.chandran stress inventory tool. The data collected was analyzed using descriptive statistics, Chi square, and the Independent Ttest. There was no significant association between perception of sexual need and perceived stress level ( $p$ $>0.05$ ).

*Junior Lecturer, College of Nursing CMC, Vellore.

**Professor, College of Nursing, CMC,Vellore.

*** Professor, College of Nursing, CMC,Vellore.

**** Professor, Christian Medical College, Vellore.
\end{abstract}

\section{Introduction}

Spinal Cord Injury ( SCI ) is a global epidemic, occurs due to trauma and other diseases, results in partial or complete paralysis.Chronic illness alters the sexual function of a patient's perception, and performance. As health professionals we too concentrate more on physical needs like nutrition, hygiene, etc and do not consider sexual need. Recognizing this the investigator conducted a descriptive study to to identify the sexual needs among patients with disability related to Spinal Cord Injury (SCI) and their spouses and related stress regarding the unmet sexual need.

\section{Objectives}

- To assess the sexual need among patients with disability related to Spinal Cord Injury (SCI) and their spouses.

- To assess the related stress level among patients with disability related to Spinal Cord Injury (SCI) and their spouses.

- To compare the perception of sexual need and stress level between these patients and their spouses.

- To associate the stress level related to sexual need of these patients with selected demographic and clinical variables.

\section{Design and sample}

\section{Method}

A descriptive comparative design was adopted for conducting the study.The study was conducted in Rehabilitation Institute, PMR OPD of the Christian Medical College, Vellore and also in and around villages within the radius of $100 \mathrm{Km} .30$ patients and their spouses who were willing to participate in the study and who could speak and write Tamil, Telugu, Hindi, Bengali and English were included in the study. The purposive sampling technique was used.

\section{Instruments}

Demographic variables such as age, sex, educational status, religion, language, number of years of married life, duration of illness, occupation, number of children and clinical data like type of paralysis ( paraplegia or quadriplegia ). No scoring was given to this. Perception of sexual need was assessed using modified Dr. Williams E Snell's combined Multi Dimensional Sexual Self Concept and Sexuality Scale.It consists of 18 statements. Each response had 4 point liker t scale as Strongly disagree, disagree, agree, and strongly agree. The scoring response was $1,2,3$, and 4 respectively.Perceived stress LevelIt consists of 15 
statements. Each response had 4 point response option as strongly disagree, disagree, agree, and strongly agree. The scoring response was $1,2,3$, and 4 respectively. Items $(1,14)$ had reverse scores.

\section{Data collection}

The patients were identified in PMR OPD through the charts registered on the day, in Rehabilitation Centre the patients were identified through the ward sister, home visit was done within $100 \mathrm{Km}$, after obtaining the address from the social worker from the rehabilitation centre. A study such as this necessitated a comfortable and trusting relationship with the individuals. Bearing in mind, the sensitivity of the issue to be discussed, the investigator took great effort to develop a good rapport with the subjects before obtaining verbal and written consent. The self administered questionnaire was then administered separately to the patients and their spouses write the investigator interviewed the patient is separately and the spouse is separately to avoid who were able to read and write. The patients and their spouses who were not able to read and patients influence on the spouse. Through this the bias of the study result was taken care.

\section{Data analysis}

Data analysis was done using descriptive statistics. Comparison of perceived sexual need and perception of stress level of patients with disability related to Spinal Cord Injury with their spouses were assessed using chi-square test.

Diagram: 1

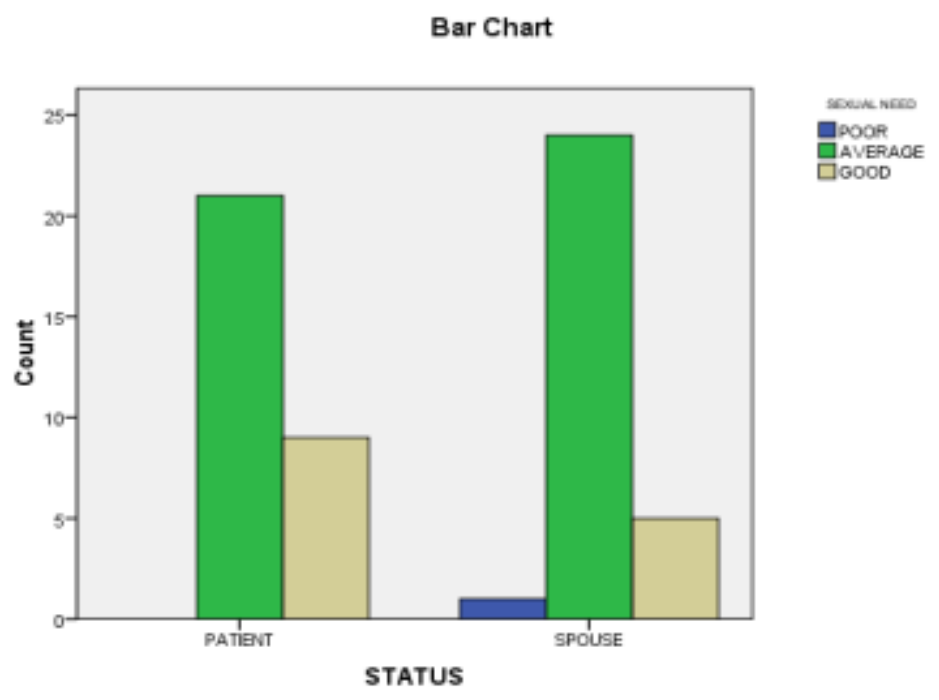

The above diagram shows that the perceived sexual need of the patient and their spouses.

\section{Diagram:2}

Bar Chart

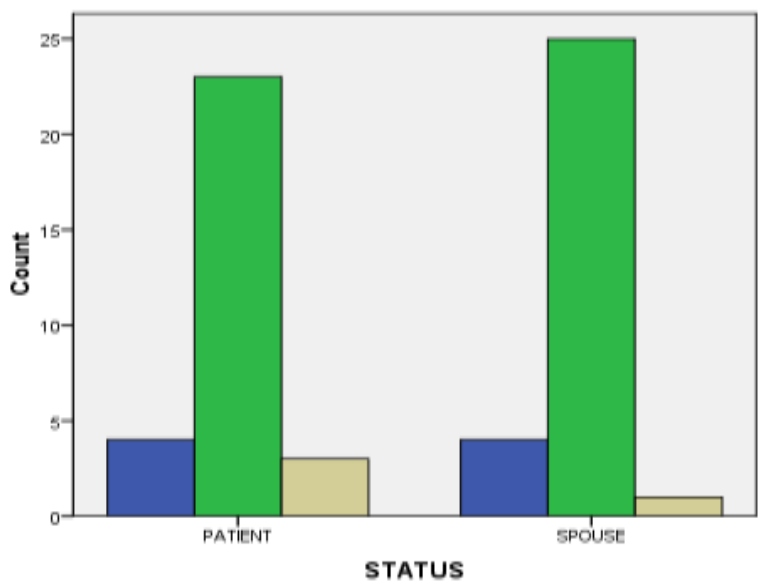


The above diagram shows that the perceived stress level of the patient and their spouses

Table 1: Significant results inperception of sexual need among patients and spouses.

\begin{tabular}{|c|c|c|c|c|c|c|c|c|c|}
\hline \multicolumn{2}{|c|}{ SECTION : III } & & & & & & & & \\
\hline \multicolumn{9}{|c|}{ Table 5 : Association between Perception of sexual need and perceived stress level } & \\
\hline \multirow[t]{3}{*}{ S.No } & \multirow{3}{*}{$\begin{array}{c}\text { Perception of } \\
\text { Sexual Need }\end{array}$} & \multicolumn{6}{|c|}{ Perceived stress Level } & \multirow[t]{3}{*}{$\mathbf{x 2}$} & \multirow{3}{*}{$\begin{array}{c}\mathbf{P} \\
\text { value }\end{array}$} \\
\hline & & \multicolumn{2}{|c|}{ Less } & \multicolumn{2}{|c|}{ Moderate } & \multicolumn{2}{|c|}{ High } & & \\
\hline & & No & $\%$ & No & $\%$ & No & $\%$ & & \\
\hline $\mathbf{1}$ & Poor Perception & $\mathbf{0}$ & $\mathbf{0}$ & 1 & 1.66 & $\mathbf{0}$ & $\mathbf{0}$ & & \\
\hline 2 & $\begin{array}{l}\text { Average } \\
\text { Perception }\end{array}$ & 5 & 8.33 & 37 & 61.66 & 3 & 5.00 & & \\
\hline 3 & Good Perception & 3 & 5.00 & 10 & 16.67 & 1 & 1.67 & 1.266 & 0.867 \\
\hline \multicolumn{8}{|c|}{$\begin{array}{l}\text { The above table shows there is no significant association between perception of } \\
\text { sexul need and perceived stress level. }(P>0.05)\end{array}$} & & \\
\hline
\end{tabular}

\section{Results and Discussion}

A total of 30 patients and 30 spouses were selected for the study by purposive sampling technique. Majority of patients with SCI belonged to 25-29yrs (3.3\%), 30- $35 \mathrm{yrs}(13.5 \%), \quad 35-39 \mathrm{yrs}(20 \%)$ and A total of $36.6 \%$ belonged to the age group of $25-39 y$ rs. $80 \%$ were from the Hindu background, $70 \%$, of them were tamil speaking and $73.4 \%$ had studied upto higher secondary.

Among 30 patients $36.3 \%$ of them agreed that sex is unhealthy after the disability where as $33.3 \%$ strongly disagreed on the issue. $63.6 \%$ agreed to have normal sexual desire and $33.3 \%$ strongly agreed to have normal sexual desire. $52.8 \%$ agreed that there is a change in their sexual pattern after the injury. In the perception of sexual need 56.6\% agreed and 30.3\% strongly agreed that the sexual need is important in their life. $39.6 \%$ were satisfied with their sexual need which was met, whereas $63.6 \%$ agreed that they adopted their own ways to have sex. $56.1 \%$ agreed that they need information about sexual need, whereas $33.0 \%$ strongly agreed that they need more information on sexual need. There is a significant association found between the perception of sexual need and their body image with the $p$ value of $0.034(p<0.034)$.

Over all $76.7 \%$ of them had average perception and $20.0 \%$ of them had good perception about their sexual need.

None of the spouses had negative thoughts about their body image.. $66 \%$ of them agreed that sexual need is important for their life. 39.6\% agreed that having sex is unhealthy after the disability. $46.2 \%$ of them agreed that there is a change in their sexual pattern after the injury. 50\% of them strongly agreed that they need information about sexual need after the injury. Among the perceived stress level $46.2 \%$ of patients strongly disagreed that feeling of sexual desire is an unpleasant thought. 50.0\% of the spouses strongly disagreed that feeling of sexual desire is an unpleasant thought and $16.5 \%$ them strongly agreed that it is an unpleasant thought. Around $50.0 \%$ of the patients had sleeplessness when they felt the sexual desire, whereas among the spouses only $19.8 \%$ agreed that they had sleeplessness when they felt the sexual desire. Around $42.9 \%$ of the patients agreed that they were depressed when they felt about the sexual desire whereas only $16.5 \%$ of spouses agreed that they were depressed. Regarding fear to engage in sexual activities, $52.8 \%$ of patients disagreed that they had fear and $62.7 \%$ of spouses disagreed that they had fear.

Among 30 patients $59.4 \%$ of them agreed that they were disappointed about their quality of sexual life and among 30 spouses only $23.1 \%$ agreed that they were disappointed about their quality of sexual life. In comparing the sexual need and stress level among paralyzed patients and their spouses it showed that $76.7 \%$ of patients had average perception, whereas it was $86.7 \%$ among spouses. Looking the above studies there are many factors involved causing stress other than the sexual need. This study also indicates that there is no significant association between the perception of sexual need and the perceived stress level with the $\mathrm{P}$ value of $0.867(\mathrm{P}>0.05)$.

\section{Conclusion}

Sexual identity is a significant and encompassing aspect of one's personality - sexuality plays an essential role in how we feel about ourselves, how we relate to others, how others relateto us. To be sure, paralysis often affects peoples' sexuality, including changes in physical functioning, sensation and response. Self-image can be shaken. People wonder if they can have sex again at all, whether they can attract a partner, whether the partner will stay, whether having children are possible. While the range of sexual options may be different, physical attraction and sexual activity are realistic expectations - no matter the level or completeness of paralysis. Sexual pleasure is possible. Paralyzed women can have children; paralyzed men can be dads. Paralyzed people can have loving and lasting relationships.

The key to successfully redefining one's sexual identity is experimentation and open communication. It helps to understand the anatomy and physiology of sexual function and sexual response. It may also help to 
connect with appropriate resources and knowledgeable health care professionals or counselors to best come to grips with the available options.

In the perceived stress level $16.7 \%$ of the patient had less stress level and $6.7 \%$ had high stress level. Most of patients had moderate stress level of 76.7\%. Among the spouses 16.7\% had less stress level and 3.3\% had high stress level. Most of them $80 \%$ had moderate stress level. Between the patients and the spouses there was an increased stress level among spouse in $3.3 \%$. The spouses who participated in my study expressed that they had stress particularly due to health issues that arise after spinal cord injury.

\section{References}

[1]. Rich Hansen Spinal Cord Injury Registry (2006) - Spinal Cord Injury Facts and Statistics. www.Spinalcord.uab.edu. Retrieved on 13.04.2010.

[2]. Indian Spinal Injuries Center. - New Delhi Peer Counseling. http:/isiconline,org/rehabilitation.peer.html . Retrieved on 17 .04 .2010 .

[3]. Titch, Radnitz and Bauman, Depression and Spinal Cord Injury: A Monozygotic Twin study, Journal of Spinal Cord Medicine, Vol. 22, No. 4, Winter, 1999, 284-287. Retrieved on 25.04.2010.

[4]. Sharma.et.al.(2006)Assessment of sexual functions after spinal cord injury in Indian Patients - International Journal of Rehabilitation Research -Volume-29 -Issue -! PP 17-25 Retrieved on 25/04/2010.

[5]. Lee.X.Blonder ,Shelby, Creed, Pettigrew, Thomas ( 2007 ) The effects of stroke disability on spousal caregivers. Journal Neuro Rehabilitation 22 P.85-92

[6]. Retrieved on 22.12.2009

[7]. Gail AllSup-Jackson (1981) Sexual Dysfunction of Stroke patients - Sexuality and Disability Vol-4 No.3 Page 161. Retrieved on 22.12.2009

[8]. Evans, Halar, DeFreece , Larsen, (1976) Multidisciplinary approach to sex education of Spinalcord-injured patients.Phy.Ther 56(5) 541-5 Retrieved on 14.02.2010

[9]. Charlifue, Gerhart, Menter, Whiteneck, Manley ( 1992 ) Sexual issues of women with spinal cord injuries. Paraplegia. 30(3):192-9. Retrieved on 14.02.2010

[10]. Larsen , Hejgaard ( 1984 ) Sexual dysfunction after spinal cord or caudaequina lesions. Paraplegia. ;22(2):66-74. Retrieved on 14.02.2010.

[11]. Alexander, Sipski Findley ( 1993 )Sexual activities, desire, and satisfaction in males pre- and post-spinal cord injury. Arch Sex Behav.22(3):217-28. Retrievd on 14.02.2010

[12]. Margareta Kreuter, AgnetaSiösteen, Fin Biering-Sørensen/January -2008 >

[13]. Iss. 1 pp. 61-69 > AbstractSexuality and sexual life in women with spinal cord injury: A controlled study Retrieved on 14.02.2010

[14]. http:;// www. disaboo,.com/sexuality-and-disability Retrieved on 14.02.2010

[15]. Stanley DucharmeSexuality and Spinal Cord Injury The Rehabilitation of People WithSpinal Cord Injury, Second Edition, Blackwell Science Publishers, Boston, 2000 Retrieved on 17.04.2010

[16]. Sexual Activities, Desire, and Sensations in paraplegic and quadriplegic ( 2006 ) The Journal of sex research Retrieved on 17.04.2010

[17]. Apparelyzed.com. Types of paralysis ( 2003-2008)Apparelyzed - Spinal Cord Injury Support . Retrieved on 23.04.2010

[18]. Sexuality and U.ca ( 2008) Teaching Sex Ed, Sex Education for Youth with Disabilities physical Disabilities. Retrieved on 12.04.2010

[19]. Stanley Ducharme(1999) sex_fatigue_depression, Depression and Spinal Cord Injury. A Monozygotic Twin Study, Journal of Spinal Cord Medicine, Vol. 22,No. 4, 284-287. Retrieved on 22.04.2010

[20]. The Free Library Journal of Sex Research , (2006) Sexual Activities, Desire, and Sensations in Paraplegic and Tetraplegic Men and Women. Retrieved on 14.02.2010

[21]. StanleyDucharme, Article of Sexuality And The Rehabilitation Process ( 2005) Retrieved on 22.04.2009.

[22]. From Wikipedia, the free encyclopedia, (2010) Spinal cord injury Retrieved on 17.04.2009

[23]. Springer Netherlands (2005), Journal on Sexuality and Women with Spinal Cord Injury Volume 23 ,Number 1 ,2005 pages 21-33 Retrieved on 14.02.2010

[24]. Robert Preidt The study in online in the Journal of Clinical Nursing. Stroke Puts Stress on Spousal Relationship Retrieved on 22.12.2009.

[25]. Snell ( 1997) Measuring multiple aspects of the sexual self -concept, The Multimensional sexual self concept questionnaire ( MSSCQ) Retrieved on 14.04.2010

[26]. Hari.S.ChandranEzine Articles.com http://EzineArticles.com/?id=48173 Assess Your Stress Using Stress Inventory Retrieved on $14 / 04 / 2010$

[27]. Brunner and Siddhartha(1992) Text book of Medical Surgical Nursing- Seventh Edition P 287 to 306

[28]. J. C. Packham et.al Long term follow up of 246 adults with juvenile idiopathic arthritis: social function, relationships and sexual activity

[29]. Rheumatology (2009) 48 (11): 1378-1381. doi: 10.1093/rheumatology/kep143First Published online: June 17, 2009

[30]. Rheumatology (2002) 41 (12): 1440-1443. doi: 10.1093/rheumatology/41.12.1440 